\title{
Minimum ST Deviation
}

National Cancer Institute

\section{Source}

National Cancer Institute. Minimum ST Deviation. NCI Thesaurus. Code C62156.

The minimum deviation (distance from baseline, positive or negative, usually measured in

$\mathrm{mm}$ ) of the ST segment, obtained from a set of measurements of the deviation of the ST segment. 